\title{
Review Article \\ Benign Hepatocellular Tumors in Children: Focal Nodular Hyperplasia and Hepatocellular Adenoma
}

\author{
Stéphanie Franchi-Abella ${ }^{1}$ and Sophie Branchereau ${ }^{2}$ \\ ${ }^{1}$ Department of Pediatric Radiology, Hôpital Bicêtre, Hôpitaux Universitaires Paris-Sud, Assistance Publique Hôpitaux de Paris, \\ 78 Rue du General Leclerc, 94278 Le Kremlin-Bicêtre, France \\ ${ }^{2}$ Department of Pediatric Surgery, Hôpital Bicêtre, Hôpitaux Universitaires Paris-Sud, Assistance Publique Hôpitaux de Paris, \\ 78 Rue du General Leclerc, 94278 Le Kremlin-Bicêtre, France
}

Correspondence should be addressed to Stéphanie Franchi-Abella; stephanie.franchi@bct.aphp.fr

Received 9 November 2012; Accepted 5 February 2013

Academic Editor: Paulette Bioulac-Sage

Copyright (C) 2013 S. Franchi-Abella and S. Branchereau. This is an open access article distributed under the Creative Commons Attribution License, which permits unrestricted use, distribution, and reproduction in any medium, provided the original work is properly cited.

\begin{abstract}
Benign liver tumors are very rare in children. Most focal nodular hyperplasia (FNH) remain sporadic, but predisposing factors exist, as follows: long-term cancer survivor (with an increasing incidence), portal deprivation in congenital or surgical portosystemic shunt. The aspect is atypical on imaging in two-thirds of cases. Biopsy of the tumor and the nontumoral liver is then required. Surgical resection will be discussed in the case of large tumors with or without symptoms. In the case of associated vascular disorder with portal deprivation, restoration of the portal flow will be discussed in the hope of seeing the involution of FNH. HepatoCellular Adenoma (HCA) is frequently associated with predisposing factors such as GSD type I and III, Fanconi anemia especially if androgen therapy is administered, CPSS, and SPSS. Adenomatosis has been reported in germline mutation of HNF1- $\alpha$. Management will depend on the presence of a predisposing factor and may include metabolic control, androgen therapy withdrawn, or closure of the shunt when appropriate. Surgery is usually performed on large lesions. In the case of adenomatosis or multiple lesions, surgery will be adapted. Close followup is required in all cases.
\end{abstract}

\section{Introduction}

Liver tumors are very rare in children, accounting for 1 to $4 \%$ of all pediatric tumors. Benign tumors account for 30 to $40 \%$ of these, with a majority of hemangiomas occurring during infancy. Focal nodular hyperplasia (FNH) and hepatocellular adenoma (HCAs) are extremely rare during childhood, and there are few published reported cases and series. Presentation, physiopathology, and management differ from adults.

We will successively review the main characteristics of $\mathrm{FNH}$ and HCA in children and discuss physiopathology, followup, and therapeutic modalities based on a systematic review of the literature and our experience.

\section{Focal Nodular Hyperplasia}

2.1. Histological Definition and Physiopathology. Focal nodular hyperplasia (FNH) is not a neoplasm but a nonspecific hyperplasic reaction to vascular abnormalities. It is a welldelimitated lesion without capsules and characterized by hepatocytic nodules separated by fibrous bands. The mass has a central stellate fibrous region containing malformed vascular structures that include large arteries, without portal veins. Bile ductular reaction is usually present at the interface between hepatocytes and fibrous bands and is highly suggestive of the diagnosis of FNH. According to some authors, in FNH, arterial blood flows from the anomalous arteries via capillaries into sinusoids adjacent to the fibrous septa. The blood in the sinusoids drains to the hepatic vein either directly or via perinodular veins. The absence of portal vein branches in FNH leads to the absence of portal blood flow.

The precise cause of FNH is unknown. Several theories have been suggested to explain the occurrence of FNH: vascularization by an anomalous large artery, acquired thrombosis, reactive hyperplasia after hepatocellular injury induced by 


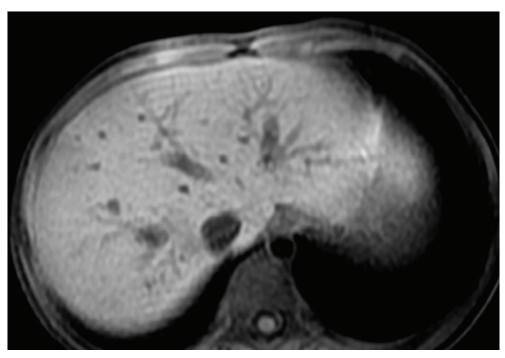

(a)

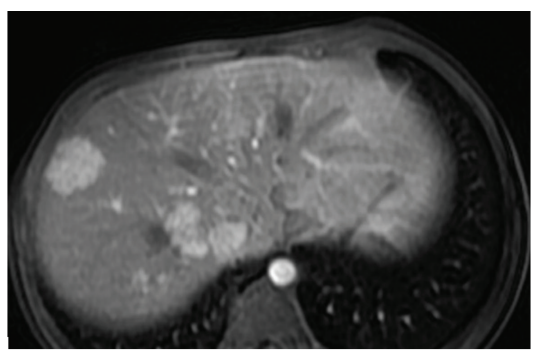

(b)

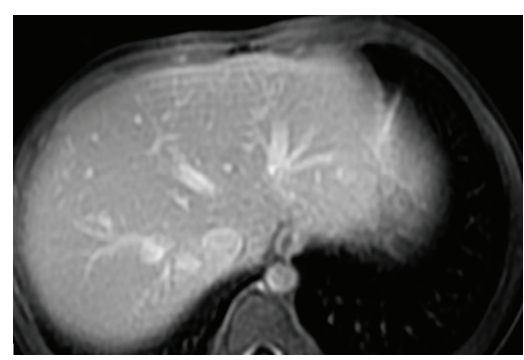

(c)

Figure 1: Nine-year-old girl with a history of metastatic right nephroblastoma treated with chemo- and radiotherapy. Liver MRI with T1-weighted images without (a) and with contrast injection at the arterial (b) and portal phases (c), performed six years after the end of treatment, displays multiple hepatic nodules, from 1 to $3 \mathrm{~cm}$ large, that enhance strongly after contrast injection at the arterial phase (b) and have almost the same signal as the surrounding liver before contrast injection (a) and at the portal phase (c). Simple clinical and imaging followup was performed (courtesy of Dr. H. Brisse, Institut Curie Paris, France).

vasculitis, or higher blood flow, either portal or arterial, compared with the surrounding tissues [1-8].

2.2. Frequency and Predisposing Factors in the Pediatric Population. FNH is very uncommon in children. About 200 cases have been reported in the literature, with few short series [9-14]. It represents from $2 \%$ to $7 \%$ of pediatric liver tumors $[10,13,15]$. FNH has been reported in all pediatric age groups, including prenatal and neonatal forms [16-18].

First known as an incidental lesion, FNH can also be associated with predisposing factors such as chemotherapy and radiation therapy in children treated for malignancy, and portal deprivation in case of congenital or surgical portosystemic shunts (CPSSs, SPSSs) (Figures 1 and 2).
In the group of children with no predisposing factors, the incidence is estimated to be $0.5 \%$. There is a female predominance as in adulthood. Mean age at diagnosis is between eight and 11 years [11].

In the population of long-term survivors of pediatric malignancy, the incidence of $\mathrm{FNH}$ is higher than in the general population and has been estimated to be $5 \%$. This represents about one-third of children with $\mathrm{FNH}$, but the number of cases reported is increasing as survivorship has significantly improved in the past decades. There is a male predominance, and mean age at diagnosis is older, between 10 and 16 years. Most patients have a history of malignancy or hematologic disorder requiring stem cell or bone marrow transplant (BMT). High doses of alkylating agents (busulfan and/or melphalan) that are very hepatotoxic and incriminated in hepatic venoocclusive disease and radiotherapy have been reported to be a risk factor for FNH. The mean time to develop FNH after treatment has been estimated to be between four and 12 years (from two to 27 years). This delay was shorter in children who had undergone high-dose chemotherapy along with BMT (7 years) (range 3-10 years). This delay was around 12 years (range 2-20 years) for patients who had not received this type of chemotherapy $[9,13,19-21]$.

FNH has also been reported in children with congenital or surgical portosystemic shunt (CPSS and SPSS) and is probably secondary to complete or partial diversion of portal blood through the shunt, which leads to impaired portal blood supply with hyperarterialization of whole or part of the liver parenchyma $[22,23]$.

2.3. Clinical Presentation. Symptomatic FNH are more frequent in children than in adults and are found in about onethird of the patients. Two-thirds of the patients with tumors larger than $7 \mathrm{~cm}$ are symptomatic [11]. The most frequent symptom is abdominal pain. More rarely, weight loss and weakness can be encountered, mostly in very large tumors, and these symptoms can give concern for malignancy.

Patients who have a history of malignancy are more likely to have small asymptomatic lesions discovered on routine surveillance (Figure 1) [13, 21]. FNH associated with CPSS can be discovered either during routine surveillance of the vascular malformation or may be fortuitously discovered and then reveal the vascular malformation [22].

2.4. Imaging Features. FNH appears on US as a welldelimitated, lobulated mass that is iso- or slightly hypo- or hyperechoic compared to the surrounding liver. On Doppler examination, it is usually fed by a large artery with a stellate structure of its branches within the tumor. Typical radiologic findings on imaging techniques using contrast enhancement include a solitary, homogeneous, and slightly hypoattenuating mass compared to the surrounding liver on unenhanced CT with rapid homogeneous contrast enhancement at the arterial phase (except for the central scar). On venous phase, the mass becomes isodense as compared to the surrounding liver, while the central scar might be enhanced on the late phase. On MRI, FNH is usually hypo- or isointense to the surrounding liver on T1-weighted images and iso- to slightly 


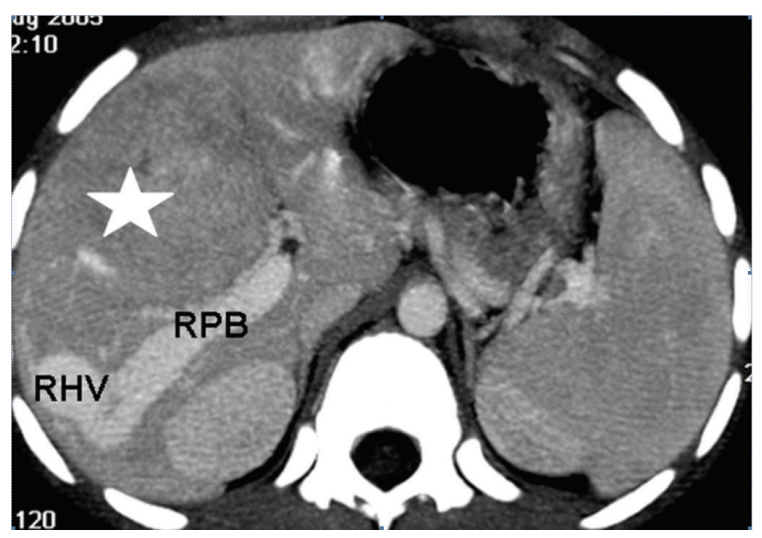

(a)

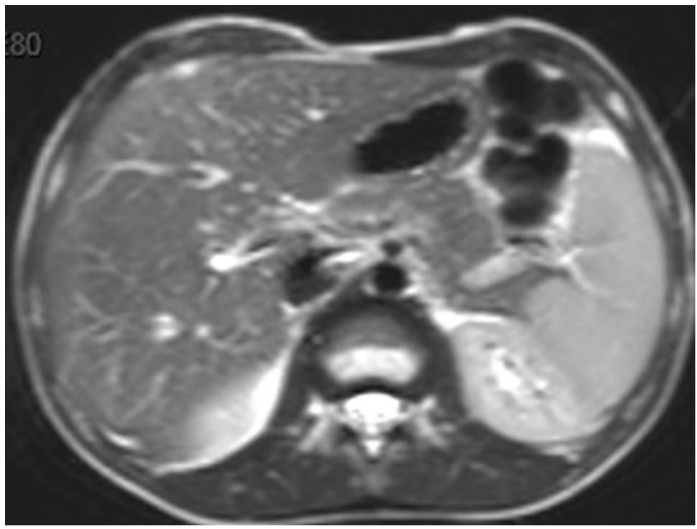

(c)

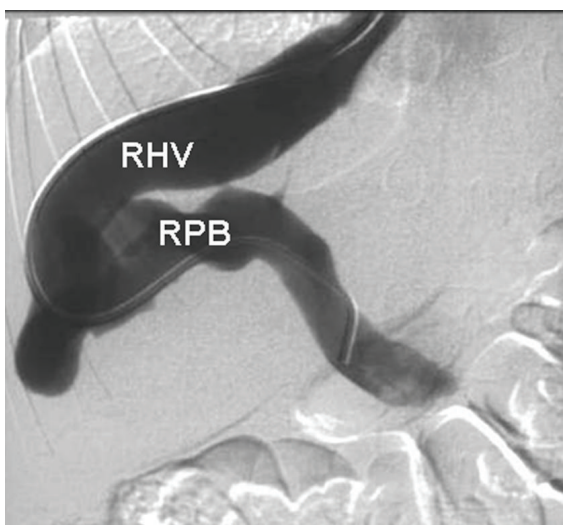

(b)

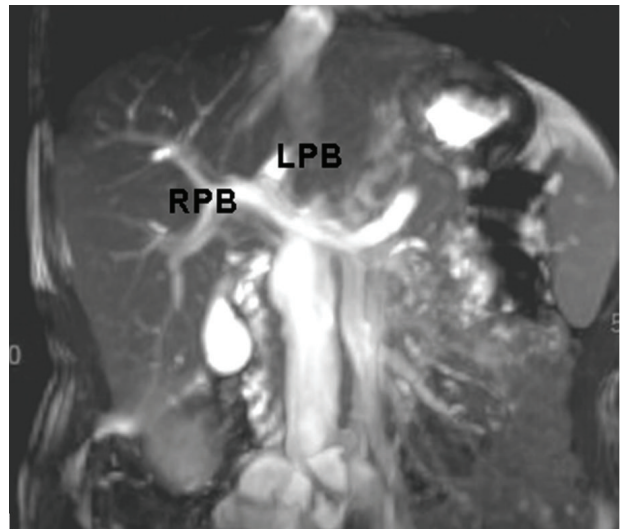

(d)

FIGURE 2: Six-year-old boy with a congenital portohepatic shunt complicated by a biopsy-proven FNH measuring $7 \mathrm{~cm}$ diameter (white star). (a) Contrast-enhanced CT scan at diagnosis shows an abnormal and large communication between the right portal branch (RPB) and the right hepatic vein (RHV). (b) Phlebography with opacification of the shunt between the RPB and the RHV. Closure of the shunt was performed by interventional radiology. (c) MRI performed seven years later shows the disappearance of FNH on the T2-weighted images. No enhancement was present at the arterial phase after gadolinium injection (not shown). (d) Note the normal aspect of the portal bifurcation (RPB and left portal branch (LPB)) on coronal MIP reconstruction of the T2-balanced sequence.

hyperintense on T2-weighted images. Enhancement after gadolinium injection is similar to that observed on a CT scan $[20,24]$. There is no calcification. In adults, due to the high specificity of CT and MRI in diagnosing FNH, there is usually no indication for biopsy in the presence of typical radiological features. In children, there is no study validating these criteria, but in our experience, when typical features of FNH are present, biopsy is not mandatory to confirm diagnosis.

The diagnosis of FNH in children can be challenging as atypical lesions occur in about two-thirds of cases, and multiple lesions are more common in children than in adults [25]. Imaging features will depend on the context. In patients with no predisposing factor, FNH are frequently larger in children than in adults (64\% of tumors $>5 \mathrm{~cm}$ versus $20 \%$ in adults [9-11, 15, 26-29]. In most cases, arterial strong enhancement of the lesions on contrast-enhanced CT or MRI is present. It can be absent if there is a complete portal diversion secondary to CPSS or SPSS, as the surrounding liver may also be fed only by the hepatic artery. A central scar is very rare in the case of small or multiple FNH. It is better seen on MRI when present [11]. Fibrolamellar hepatocarcinoma is an important differential diagnosis as it frequently presents with an area of scarring. Patterns that are in favor of fibrolamellar hepatocarcinoma are lobulated margins of the tumor, the presence of calcifications, the large size of the central scar, the tumor heterogeneity before injection and at the arterial phase, and the presence of lymphadenopathies and/or the presence of metastases [30].

In the group of children with a history of chemo- and/or radiotherapy, a major concern is to differentiate benign and malignant processes. Strong enhancement at the arterial or early portal phase is important to differentiate $\mathrm{FNH}$ or "FNHlike" lesions from metastases that usually remain hypointense on arterial or early portal phase when compared to the surrounding liver [21]. Even if not presenting the typical diagnostic criteria for $\mathrm{FNH}$, multiple liver lesions strongly enhancing at the arterial phase after injection in a long-term cancer survivor are highly suggestive of the diagnosis, and 


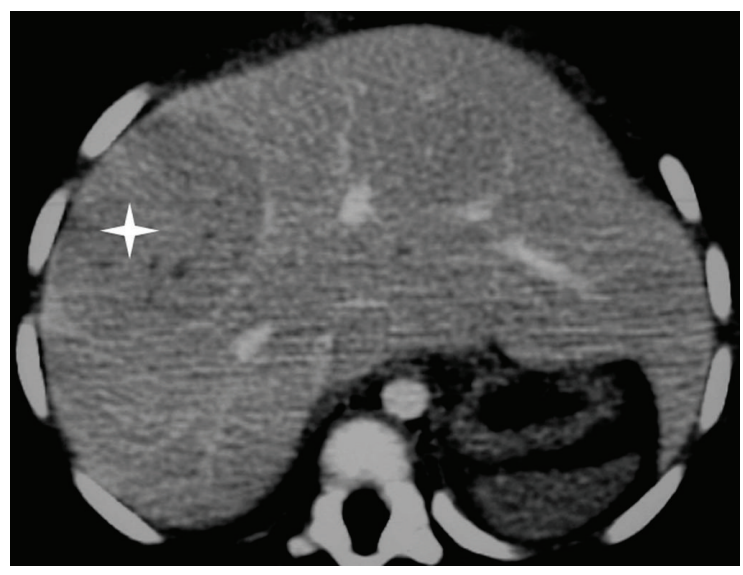

(a)

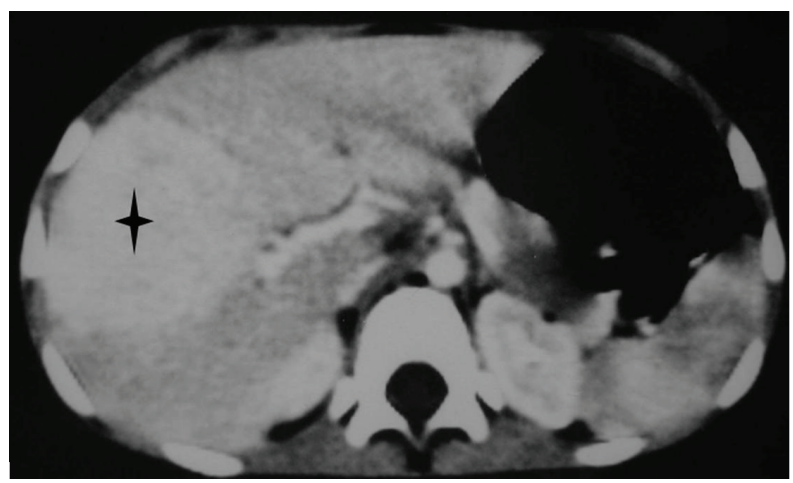

(c)

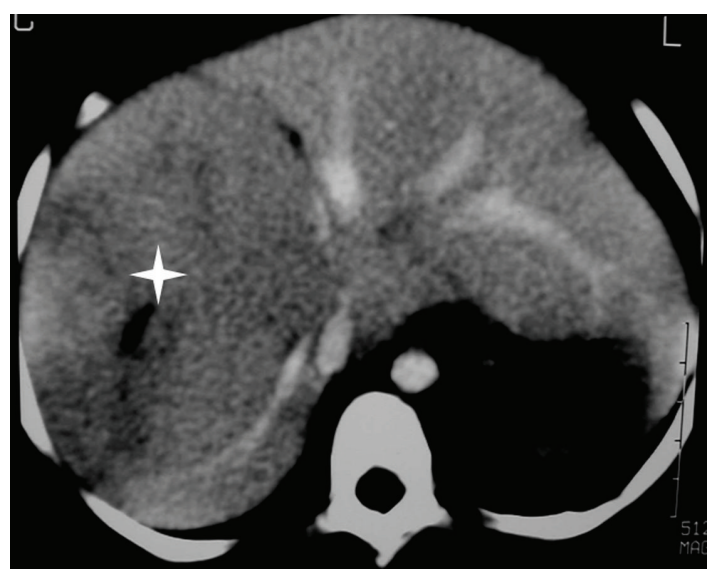

(b)

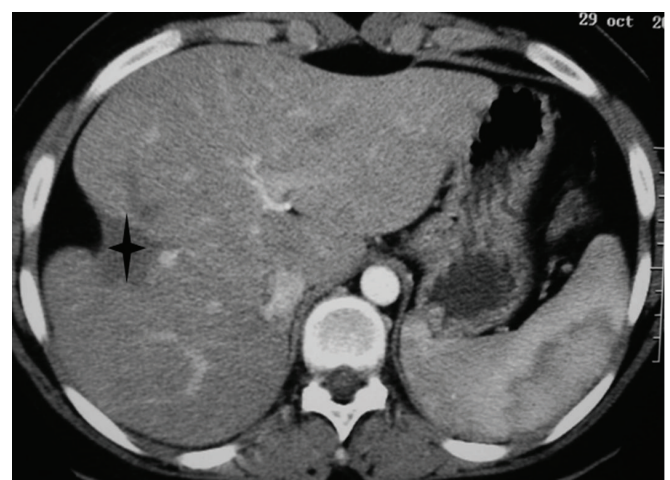

(d)

FIGURE 3: Spontaneous evolution of fortuitously discovered FNH in two children. (a) and (b): three-year-old girl with sickle-cell disease. CT scan after contrast injection at the portal phase at diagnosis (a). And three years later (b) shows growth of the tumor from 5 to $12 \mathrm{~cm}$ diameter. (c) and (d): eight-year-old girl. CT scan after contrast injection at diagnosis (c) and 12 years later (d) shows the spontaneous disappearance of the $5 \mathrm{~cm}$ diameter tumor with capsular retraction.

conservative treatment with imaging surveillance should be recommended (Figure 1) [11, 13, 21, 31].

2.5. Natural History and Management. In the literature, few patients had conservative management of FNH. The natural history of these tumors is poorly known in children. All kinds of spontaneous evolution have been described, from spontaneous involution to growth (Figure 3) [11].

In the literature, $78 \%$ of the patients with no history of malignancy or hemopathy had a surgical resection. Most masses were large $[11,12]$.

In our practice, when the imaging features are typical on MR and/or CT, the patient is asymptomatic and there is no associated vascular disorder, biopsy is not performed, and conservative management is proposed with a prolonged followup by ultrasound to show if there is an increase in size.

When the aspect is not typical, biopsies of the mass and the nontumoral liver are performed to assess the diagnosis of the tumor and search for associated abnormalities of the liver that could be part of an unknown predisposing factor for a tumor.

Surgery is sometimes performed in the case of very large lesions, symptoms, and/or impairment of physical activities.
Recurrence of FHN after surgery has been reported in one case in the literature, and we have a personal case, not published [32].

FNH secondary to CPSS requires special management as the closure of the shunt with restoration of intrahepatic portal flow may lead to shrinkage of the tumor, as shown in previous cases (Figure 2). That is why, whatever are the size of the tumor, the number of lesions, and their location, closure of the shunt should be performed when possible. We usually perform a biopsy of the tumor and the nontumoral liver to confirm the diagnosis of benign liver proliferation and exclude a hepatoportal sclerosis that would contraindicate the closure of the shunt [22].

In the case of SPSS, closure of the shunt should be discussed in regard to the patient's history. Restoration of intrahepatic portal flow by making a mesenterico-rex bypass should be performed when possible, mostly in the case of portal obstruction with cavernomatous transformation [23].

\section{Hepatocellular Adenoma}

3.1. Histopathological Definition. Hepatocellular adenomas (HCAs) are extremely rare during childhood. They are benign 
liver tumors that represent a heterogeneous group in which histopathological features may vary according to the etiological background. Classically, HCAs are soft, well-demarcated tumors with little or no fibrous capsule. They are composed of liver cell plate mildly thickened or irregular. They are supplied by thin-walled arteries without other portal tract elements (connective tissue, bile ducts, or ductular reaction).

In adults, genomic and molecular studies together with the analysis of genotype/phenotype correlations have led to the recognition of four major HCA subgroups: HNF1- $\alpha-$ inactivated HCA, $\beta$-catenin-activated HCA, and two forms of HCA without mutation of HNF1- $\alpha$ or $\beta$-catenin presenting either with or without inflammation. These different subtypes display variable clinical behavior, imaging findings, and natural history that have recently been well described [3336]. To our knowledge, the only study concerning the profile of HCA genotype-phenotype in children concerns glycogen storage disease type I (GSD) and showed a high frequency of $\beta$-catenin mutations and lack of HNF $1 \alpha$ inactivation [37].

HCA formation is complex and varies according to the etiological background. Natural history and management vary with the context.

3.2. Epidemiology and Predisposing Factors in Children. According to the rare published pediatric series, HCA occurs in 0 to $21 \%$ of pediatric benign liver tumors. Differences in the frequency between series are probably related to the differences in patients' recruitments. The largest pediatric series reported $22 \mathrm{HCA}$ in a 12 -year period [12, 38-41].

Most HCAs are diagnosed during the teenage years (the mean age at diagnosis is around 14 years). HCAs reported before the age of one year are exceptional, the youngest patient being three weeks old in a context of multiple congenital anomalies [42].

Sex ratio varies with series, but the female predominance observed in adults is not the rule in children, and male predominance is observed in several series [38].

During childhood, HCA can be sporadic but is more frequently associated with predisposing factors such as GSD type I and III, anabolic androgenic steroid treatments with or without Fanconi anemia, congenital or surgical portosystemic shunt (CPSS, CPSS), germline mutation of HNF1$\alpha$ gene, and familial adenomatosis polyposis (Figures 4,5 , and 6) $[22,23]$. Hurler syndrome, Turcot syndrome, Lynch syndrome, immunodeficiency syndrome, tyrosinemia, and galactosemia have also been reported, and we have the personal unpublished experience of teenage girls with multiple HCA associated with Glanzmann's thrombasthenia treated by progestative therapy [43].

3.3. Imaging Features. Making the diagnosis of HCA by imaging can be challenging. In adults, major improvements in knowledge of HCA have been gained during recent years. Correlations of imaging with the genotype/phenotype classification proposed by the "Bordeaux" experience have made it possible to distinguish specific imaging patterns in relation with the two major subtypes, inflammatory HCA and HNF $1 \alpha$-mutated HCA that account for $80 \%$ of all cases in adult series $[34,35,44]$. Very little data on the imaging features of HCA are available for children.

Ultrasonography is usually the first exam performed in children for the evaluation of abdominal disorders and the first screening tool during followup in predisposed children, but it can miss small nodules isoechoic to the liver, especially in a steatotic liver. HCAs are typically heterogeneous and are well-delimited solid masses with vessels within the mass (Figure 5).

Magnetic resonance imaging (MRI) is the best technique to depict lesions. HCAs patterns on MRI will depend on the amount of fat, hemorrhage, and necrosis within the mass. HCA are frequently heterogeneous on T1- and T2-weighted images (WIs) but with a high signal on T2 WI. Fat component in HCA is well demonstrated with chemical shift sequences as in "in-phase and out-of-phase" T1 sequence. It can also be shown by sequences with fat saturations that are less sensitive. When present, it can help diagnosis. Early enhancement after contrast injection is observed in most cases. An enhanced pseudocapsule can be visible on delayed acquisition. Washout should not be too early (Figure 4 ). Diffusion sequences may help in the detection of small lesions. CT can also display fat within the tumor, heterogeneous content and early arterial enhancement [45]. In the presence of CPSS or SPSS, both HCA and nontumoral liver will lack portal vascularization, causing the absence of the early arterial enhancement classically observed in HCA, as both the nodule and the surrounding liver only have arterial supplies.

When sporadic, HCA are frequently large solitary masses. In predisposed children, multiple HCA are more frequently observed. The term "adenomatosis" was first used in adult literature, and its definition excluded patients with GSD and steroid treatment [46]. This term has also been used for adenomas related to HNF1- $\alpha$ mutation (Figure 4).

Except for children with GSD, there are no published recommendations about screening protocols for HCA in patients presenting predisposing factors. At least annual ultrasonography should be performed, but MRI with its better sensitivity for the detection of liver tumors mostly in older children could be part of the systematic screening using T1-WI with fat suppression or chemical-shift sequences and T2-WI, diffusion sequences, and dynamic gadolinium injection when a lesion is detected on initial sequences.

An important concern is the detection of malignant transformation. This may be challenging and only possible with histology. Increasing size of the tumor and modifications of its aspect can be signs of malignant transformation. The kinetics of enhancement after contrast injection are important, and early washout after early enhancement at the arterial phase is suggestive of HCC transformation.

In most cases, histologic assessment of the tumor is necessary to adapt the management. In sporadic cases with no known predisposing factor, it is worthwhile to perform a biopsy on the nontumoral liver in order to depict an unknown underlying liver disease.

3.4. Natural History and Predisposing Factors. In sporadic cases or when no predisposing factor is known, HCA can be 


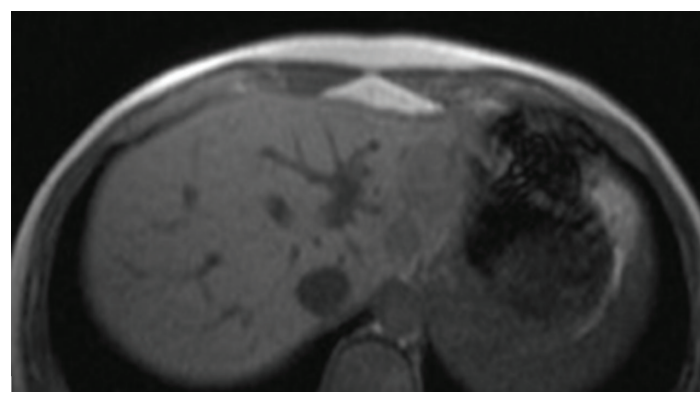

(a)

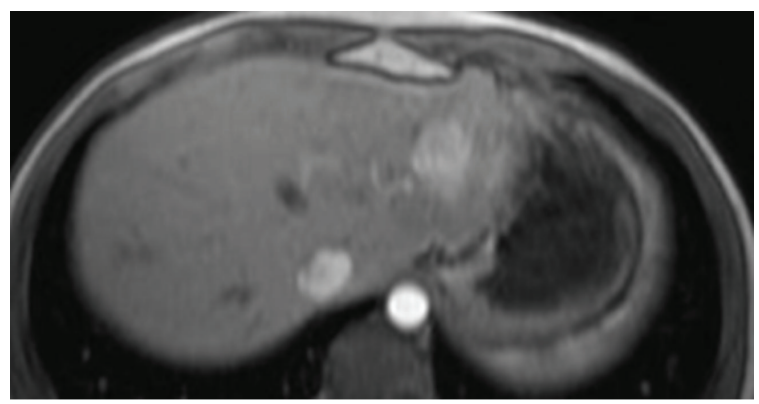

(c)

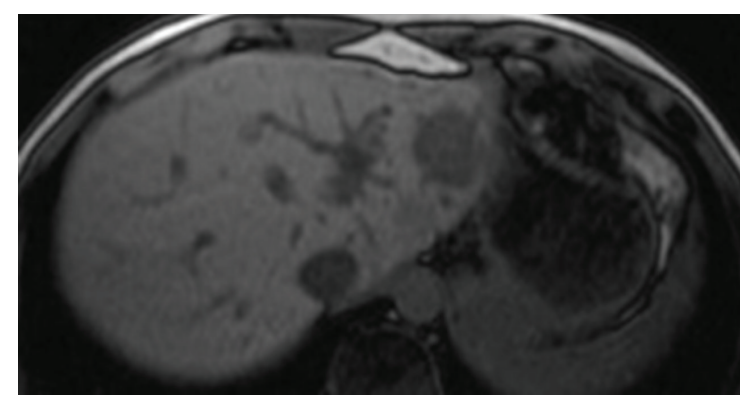

(b)

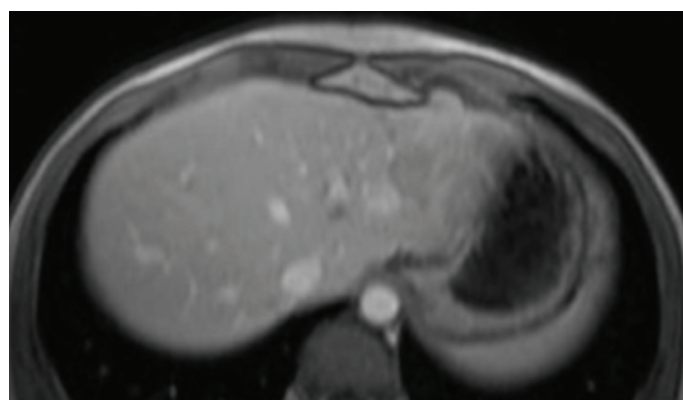

(d)

FIgURE 4: Adenomatosis related to HNF1- $\alpha$ germline mutation aspect on MRI in a 14-year-old girl: (a) and (b): T1 WI with chemical shift shows two lesions in the left lobe of the liver with drop of the signal of the largest lesion on the out-phase sequence that reveals the presence of fat in the tumor. (c) and (d): T1 WI after contrast injection shows early arterial enhancement of the largest lesion with washout in the late portal phase.

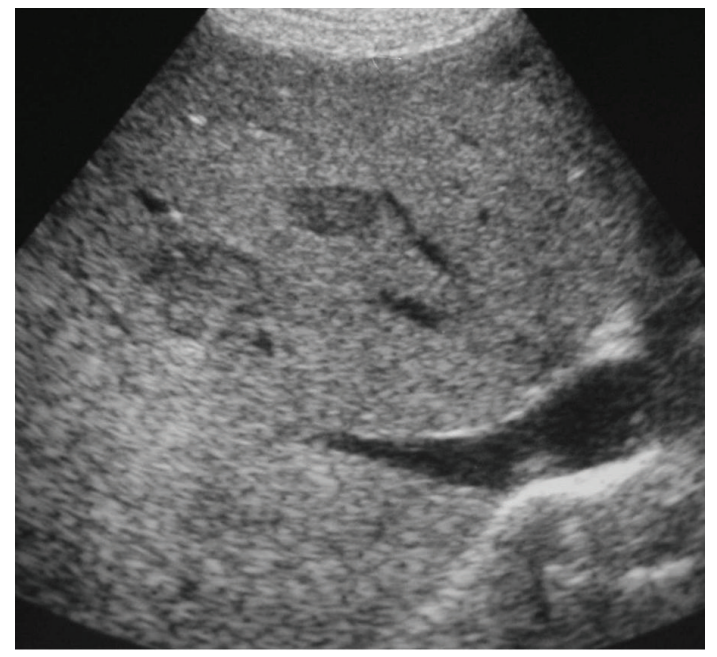

(a)

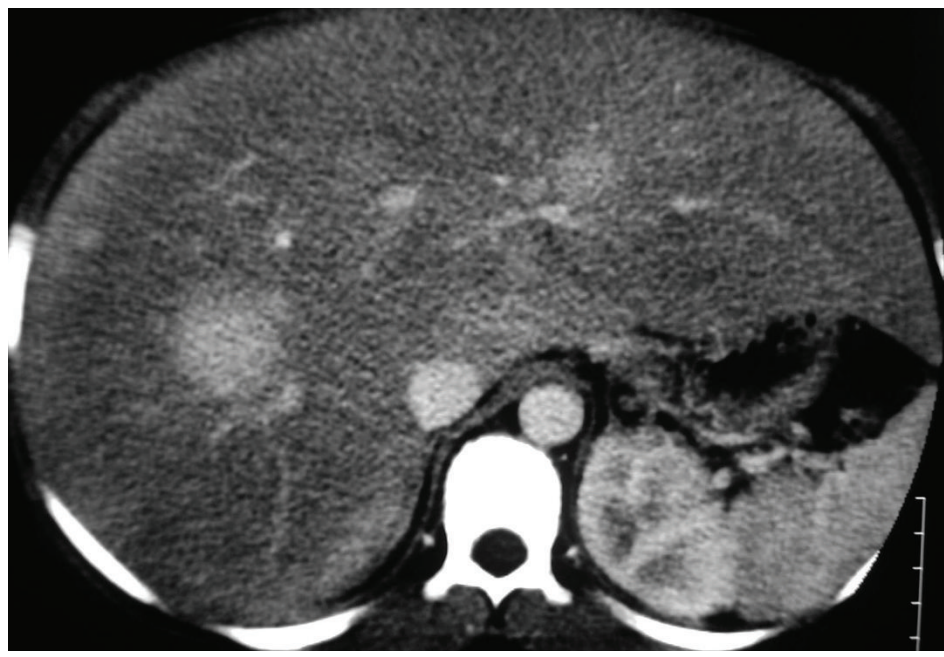

(b)

FIGURE 5: Fourteen-year-old boy with glycogen storage disease type I and multiple HCA measuring from 1 to $3 \mathrm{~cm}$ diameter. (a) US shows an enlarged hyperechoic liver (steatotic) with well-delimited hypoechoic nodules. (b) CT performed at the arterial phase after contrast injection shows enlarged steatotic liver with multiple nodules that are strongly enhanced.

found incidentally during imaging for unrelated pathology, but most often patients present with abdominal pain or palpable mass to the right upper quadrant or the epigastric region.

The two major concerns with HCA are hemorrhage and malignant transformation into HCC.
Hemorrhage is one of the most important complications of HCA. The maximum risks of bleeding and rupture have been estimated in 27.2 and 17.5 percent of patients respectively in a systematic review with the youngest patient being 14 years old [47]. Two types of hemorrhagic changes can take place in HCA: internal hemorrhage usually mixed with 


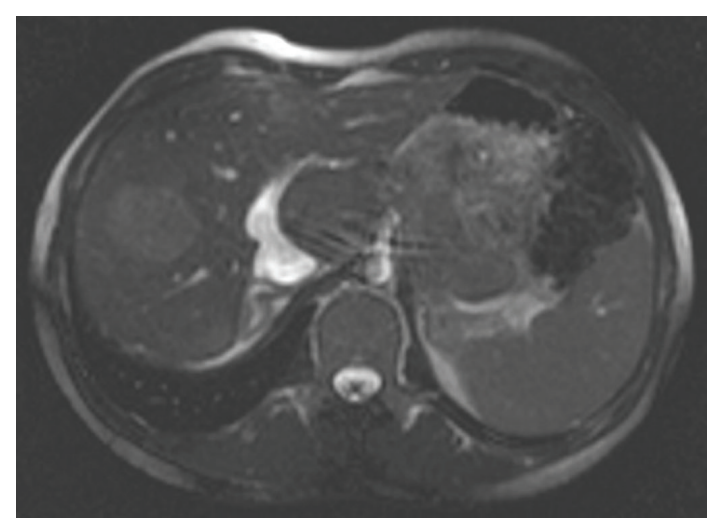

(a)

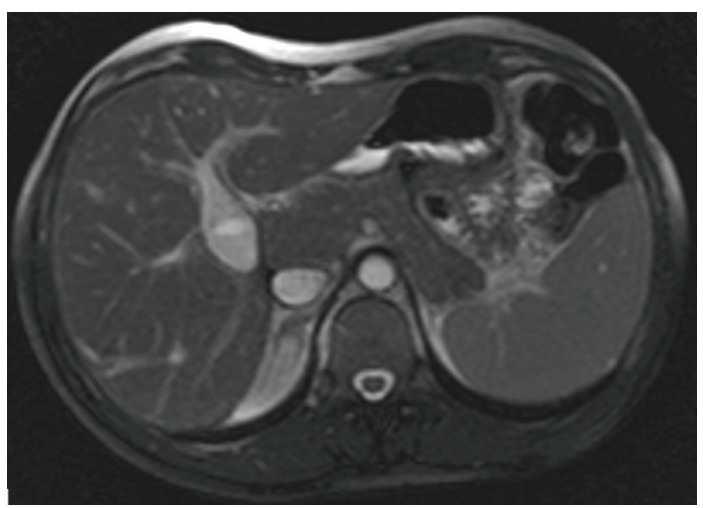

(c)

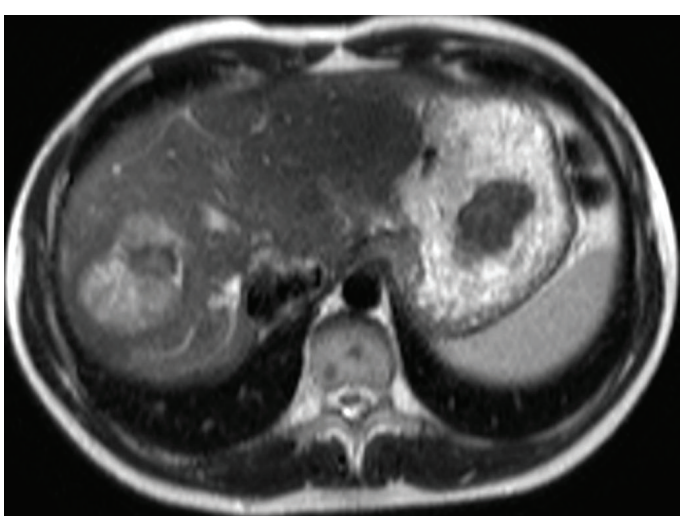

(b)

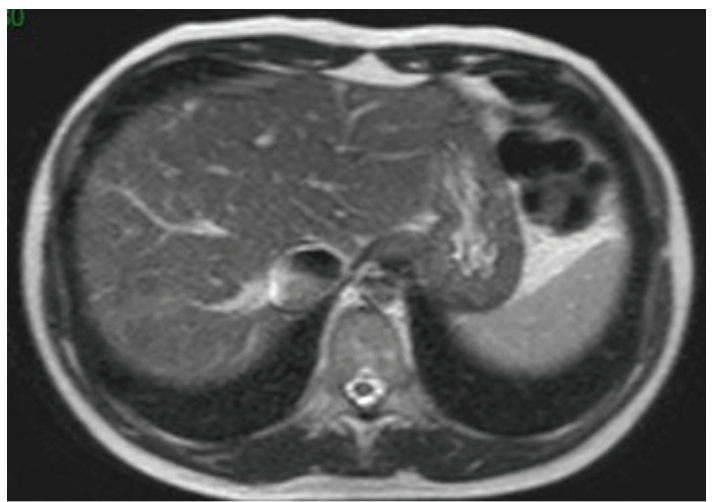

(d)

FIgURE 6: Adenoma associated with CPSS. Aspect on MRI at diagnosis and 10 months after surgical closure of the shunt: (a) T2 WI-balanced sequence shows the CPSS consisting of a patent ductus venosus. Note that the tumor is not easily visible in this sequence. (b) The $4 \mathrm{~cm}$ diameter HCA lies in segment 8, and it is better seen on T2 WI and appears heterogeneous and mainly hyperintense compared to the surrounding liver. MRI performed 10 months after surgical closure of the shunt (c) shows the complete disappearance of the tumor (d).

necrotic changes (usually in tumors larger than $4 \mathrm{~cm}$ ) and spontaneous rupture with possible subcapsular hematoma and/or hemoperitoneum. Severe abdominal pain with possible hemodynamic disorders or even collapse can occur during intraperitoneal or intratumoral hemorrhage of HCA. Fatal issues have been reported in young patients with familial adenomatosis related to HNF1- $\alpha$ mutation and in FA. Hemorrhage has been reported in FA even after discontinuation of androgen therapy $[48,49]$.

Malignant transformation of HCA into HCC is rare, even in adults, and remains controversial in the literature [50]. Among the 50 cases (4.2\%) of malignant transformation reported in a systematic review of $1635 \mathrm{HA}$ (glycogenosis and adenomatosis were excluded), there were no pediatric cases [51]. In children, exceptional malignant transformations of HCA have been reported, mainly associated with GSD, FA with steroid therapy, and CPSS [22, 33, 51-55]. HCA associated with GSD type I displays high frequency of $\beta$-catenin mutation that could explain the high frequency of malignant transformation [37]. In adults, risk groups for malignant transformation of HCA are male gender, tumors larger than $5 \mathrm{~cm}$, and $\beta$-catenin-activated HCA, and even though no data are yet published in the literature, these criteria should be taken into account when managing children. [51-53, 56].

In children with predisposing factors, the natural history and management of HCA will depend on the underlying pathology.

Concerning HCA complicating GSD type I and III, most series or cases are associated with type I. In a series of 43 patients with GSD, about $52 \%$ of patients with type I and $25 \%$ of patients with type III glycogen storage disease had HCA [57]. Natural history and pathophysiological conditions remain poorly understood. HCA develop predominantly during and after puberty, between the ages of 10 and 20 years, and the incidence of new HCA appears to decrease after 20 years of age. The youngest patient presenting with HCA was 3.6 years old [58]. The male to female ratio is $1 / 1$. The increased incidence of HCA development during adolescence may be related to suboptimal metabolic control during this period and/or to pubertal hormone secretion. Metabolic control seems to be an important factor for HCA development. Considerable alteration of lipid metabolism is a feature encountered in GSD associated with HCA formation. 
According to some authors, GSD type I displays a very high level of de novo fatty acid synthesis, which is known to play a role in tumorigenesis $[58,59]$.

Malignant transformation leading to HCC has been reported in adult patients and is probably related to the high frequency of $\beta$-catenin mutation $[37,52,54,55]$. Recommendations for screening HCA by the "European Study of Glycogen Storage Disease Type I b" include an annual abdominal ultrasonography from birth to 10 years old, then every six months after 10 years of age.

On liver ultrasound, HCAs are usually well-delimited round nodules hypoechoic compared to steatosis surrounding the liver parenchyma. If liver HCA is detected, ultrasonography should be performed every three months, associated with dosage of serum $\alpha$-foetoprotein and carcinoembryonic antigen. CT or MRI with contrast injection will be performed on demand if the nodules increase in size, or if features suggestive of malignant transformation appear [60]. However, the difficulty in detecting HCA in bright liver with attenuation of US beam makes MRI more reliable for screening in some patients.

Management of HCA includes metabolic control as, when metabolic control is achieved, regression of HCA has been reported [61]. Surgery will depend on the presentation, ranging from tumorectomy to liver transplantation.

In children with Fanconi Anemia (FA) and androgen therapy with or without FA, liver tumors can occur and concern about 3\% of patients [62]. Most are HCAs, but hepatocellular carcinoma (HCC), focal nodular hyperplasia (FNH), hepatoblastoma have also been reported [63-65]. Treatment of FA is based on androgen therapy and BMT as in other forms of aplastic anemia. Liver tumors can occur in FA patients in the absence of androgen therapy but are mainly associated with it. FA patients usually start androgens when they are young, at a median age of 7.5 years. Median duration of treatment with androgen prior to HCA or HCC diagnosis is four years, and median age at diagnosis of HCA is 12 years [64]. Association of HCA and HCC has been reported in several patients, and there is more likely to be transition from HCA into HCC as suggested by the presence of foci of HCC within HCA [63]. The median age at diagnosis of HCC in FA is 13.4 years [64]. Several factors may play a role in the development of HCA in FA: (i) genetic disorders and chromosomal defects allow mutagenesis and liver cell proliferation, (ii) chronic iron overload, which is frequently encountered even in the absence of blood transfusion or hemochromatosis, probably has a carcinogenetic effect [66, 67], and (iii) androgen therapy presents hepatic oncogenic properties $[63,64]$. Screening for HCC in this context is difficult because HCC may occur despite typical radiological patterns of HCA. The $\alpha$-foetoprotein test is not reliable as this biomarker has been found to be increased in about $85 \%$ of FA patients [67]. Close followup by imaging is mandatory for early diagnosis of HCA. When HCA is diagnosed, discontinuation of androgen therapy should be discussed if bone marrow function permits, as tumors may regress if androgens are withdrawn. Regression of HCA has also been reported after BMT. Close followup to depict transformation into HCC is mandatory and should be prolonged as late development of liver tumors (up to 24 years) is possible. Hemorrhagic complications have also been reported even after discontinuation of androgen therapy [49].

Heterozygous germline mutations of the hepatocyte nuclear factor-HNF1 alpha are associated with liver adenomatosis and maturity onset diabetes of the young (MODY 3) $[46,68-$ 71]. Expression of the phenotype is variable for diabetes and adenomatosis. Severe intraperitoneal hemorrhages related to complicated adenomas have been reported, with a fatal issue in a sixteen-year-old girl [69]. Cases of malignant transformation have also been reported [68]. Adenomatosis has been reported in teenage patients with the youngest being 14 years old [48]. Systematic screening should be performed in relatives of patients with liver adenomatosis and should start at the age of ten years. Ultrasonography is a good screening tool, but adenomas may be difficult to diagnose in some patients. MRI with contrast injection should be performed to increase the sensitivity of screening (Figure 4). A CT scan with contrast injection can also be proposed if MRI is not available. Adenomas are often steatotic. Serum $\alpha$-foetoprotein levels should also be part of the screening. If liver adenomatosis is detected, survey and preventive surgical treatment should be discussed. Criteria that guide treatment include the number and size of the lesions, the presence of symptoms, and the surgical risk incurred by the patient.

Congenital or Surgical portosystemic shunts are associated with HCA, as reported in several cases [22, 23, 72]. Partial or complete diversion of the portal flow through the shunt leads to an abnormal hepatic circulation that may cause hepatocytic proliferation with nodule formation [8]. Regression of adenomas has been observed after closure of CPSS and restoration of portal blood flow (Figure 6).

3.5. Management. It is now well established in adults that complications depend not on the number of lesions but on the histologic subtype and size of the tumor. In adults, complete surgical resection is an effective option for HCA larger than $5 \mathrm{~cm}$ or in male or if HCA is associated with GSD. In our personal pediatric experience and in the pediatric literature, HCAs which are frequently larger than $5 \mathrm{~cm}$ are resected $[38,40]$. Surgical resection should also be discussed in case of $\beta$-catenin mutation or uncertain diagnosis. Some authors propose resection of smaller HCA, between 3 and $5 \mathrm{~cm}$, because of reported cases of malignant transformation $[53,73]$. The surgical technique will depend on the context, location, and size of the tumor, and it may consist of a tumorectomy, atypical resection, or hepatectomy. Liver transplantation has been proposed by some authors in the case of multiple lesions [48, 74, 75]. In our experience and as suggested by Dokmak and coll. in adult patients, we propose a conservative treatment for multiple HCA or adenomatosis, involving resection of the largest tumors and close followup of the remaining small lesions with iterative resection if necessary. The place of percutaneous ablation using either radiofrequency, cryotherapy, or other techniques is still unclear [76].

Embolization can be performed in the case of hemorrhage. 
With predisposing factors such as GSD, androgen steroid therapy, CPSS, or SPSS, regression of HCA has been observed with metabolic control, androgen withdrawn, and closure of the shunt, respectively.

\section{Conclusion}

Most FNH remain sporadic during childhood, but predisposing factors exist, as follows: long-term cancer survivor (with an increasing incidence) and portal deprivation in CPSS and SPSS. The aspect is atypical on imaging in twothirds of cases. Biopsy of the tumor and the nontumoral liver is then required. Surgical resection will be discussed in the case of large tumors with or without symptoms. In the case of associated vascular disorder with portal deprivation, restoration of the portal flow will be discussed. This will be done either by closure of a congenital portosystemic shunt or by making a mesenterico-rex bypass in the cavernous transformation of the portal vein in the hope of seeing the involution of FNH.

HCA, which is very rare in children, is frequently associated with predisposing factors such as GSD type I and III, Fanconi anemia especially if androgen therapy is administered, CPSS, and SPSS. Adenomatosis has been reported in germline mutation of HNF1- $\alpha$. Management will depend on the presence of a predisposing factor and may include metabolic control, androgen therapy withdrawn, or closure of the shunt when appropriate. Surgery is usually performed on large lesions. In the case of adenomatosis or multiple lesions, surgery will be adapted. Close followup is required in all cases.

\section{References}

[1] Y. Fukukura, O. Nakashima, A. Kusaba, M. Kage, and M. Kojiro, "Angioarchitecture and blood circulation in focal nodular hyperplasia of the liver," Journal of Hepatology, vol. 29, no. 3, pp. 470-475, 1998.

[2] I. R. Wanless, C. Mawdsley, and R. Adams, "On the pathogenesis of focal nodular hyperplasia of the liver," Hepatology, vol. 5, no. 6, pp. 1194-1200, 1985.

[3] S. Rebouissou, P. Bioulac-Sage, and J. Zucman-Rossi, "Molecular pathogenesis of focal nodular hyperplasia and hepatocellular adenoma," Journal of Hepatology, vol. 48, no. 1, pp. 163-170, 2008.

[4] B. N. Nguyen, J. F. Fléjou, B. Terris, J. Belghiti, and C. Degott, "Focal nodular hyperplasia of the liver: a comprehensive pathologic study of 305 lesions and recognition of new histologic forms," American Journal of Surgical Pathology, vol. 23, no. 12, pp. 1441-1454, 1999.

[5] H. Kumagai, T. Masuda, H. Oikawa, K. Endo, M. Endo, and T. Takano, "Focal nodular hyperplasia of the liver: direct evidence of circulatory disturbances," Journal of Gastroenterology and Hepatology, vol. 15, no. 11, pp. 1344-1347, 2000.

[6] P. Bioulac-Sage, C. Balabaud, and I. R. Wanless, "Diagnosis of focal nodular hyperplasia: not so easy," American Journal of Surgical Pathology, vol. 25, no. 10, pp. 1322-1325, 2001.

[7] I. R. Wanless, S. Albrecht, J. Bilbao et al., "Multiple focal nodular hyperplasia of the liver associated with vascular malformations of various organs and neoplasia of the brain: a new syndrome," Modern Pathology, vol. 2, no. 5, pp. 456-462, 1989.

[8] F. Kondo, "Benign nodular hepatocellular lesions caused by abnormal hepatic circulation: etiological analysis and introduction of a new concept," Journal of Gastroenterology and Hepatology, vol. 16, no. 12, pp. 1319-1328, 2001.

[9] A. J. Towbin, G. G. Luo, H. Yin, and J. Q. Mo, "Focal nodular hyperplasia in children, adolescents, and young adults," Pediatric Radiology, vol. 41, no. 3, pp. 341-349, 2011.

[10] D. Reymond, J. Plaschkes, A. R. Luthy, K. Leibundgut, A. Hirt, and H. P. Wagner, "Focal nodular hyperplasia of the liver in children: review of follow-up and outcome," Journal of Pediatric Surgery, vol. 30, no. 11, pp. 1590-1593, 1995.

[11] T. Lautz, N. Tantemsapya, A. Dzakovic, and R. Superina, "Focal nodular hyperplasia in children: clinical features and current management practice," Journal of Pediatric Surgery, vol. 45, no. 9, pp. 1797-1803, 2010.

[12] I. N. Kochin, T. A. Miloh, R. Arnon, K. R. Iyer, F. J. Suchy, and N. Kerkar, "Benign liver masses and lesions in children: 53 cases over 12 years," Israel Medical Association Journal, vol. 13, no. 9, pp. 542-547, 2011.

[13] C. Icher-De Bouyn, J. Leclere, G. Raimondo et al., "Hepatic focal nodular hyperplasia in children previously treated for a solid tumor: incidence, risk factors, and outcome," Cancer, vol. 97, no. 12, pp. 3107-3113, 2003.

[14] D. Gobbi, P. D. Igna, C. Messina, E. Cesca, and G. Cecchetto, "Focal nodular hyperplasia in pediatric patients with and without oncologic history," Pediatric Blood and Cancer, vol. 55, no. 7, pp. 1420-1422, 2010.

[15] J. T. Stocker and K. G. Ishak, "Focal nodular hyperplasia of the liver: a study of 21 pediatric cases," Cancer, vol. 48, no. 2, pp. 336-345, 1981.

[16] J. Kang, H. J. Choi, E. Yu, I. Hwang, M. K. Young, and J. C. Hee, "A case report of fetal telangiectatic focal nodular hyperplasia," Pediatric and Developmental Pathology, vol. 10, no. 5, pp. 416417, 2007.

[17] N. Okamura, H. Nakadate, K. Ishida et al., "Telangiectatic focal nodular hyperplasia of the liver in the perinatal period: case report," Pediatric and Developmental Pathology, vol. 8, no. 5, pp. 581-586, 2005.

[18] B. M. Petrikovsky, H. L. Cohen, P. Scimeca, and E. Bellucci, "Prenatal diagnosis of focal nodular hyperplasia of the liver," Prenatal Diagnosis, vol. 14, no. 5, pp. 406-409, 1994.

[19] R. Masetti, C. Biagi, K. Kleinschmidt et al., "Focal nodular hyperplasia of the liver after intensive treatment for pediatric cancer: is hematopoietic stem cell transplantation a risk factor?" European Journal of Pediatrics, vol. 170, no. 6, pp. 807-812, 2011.

[20] K. J. Mortele, M. Praet, H. Van Vlierberghe, M. Kunnen, and P. R. Ros, "CT and MR imaging findings in focal nodular hyperplasia of the liver: radiologic-pathologic correlation," American Journal of Roentgenology, vol. 175, no. 3, pp. 687-692, 2000.

[21] E. A. Smith, S. Salisbury, R. Martin, and A. J. Towbin, "Incidence and etiology of new liver lesions in pediatric patients previously treated for malignancy," American Journal of Roentgenology, vol. 199, no. 1, pp. 186-191, 2012.

[22] S. Franchi-Abella, S. Branchereau, V. Lambert et al., "Complications of congenital portosystemic shunts in children: therapeutic options and outcomes," Journal of Pediatric Gastroenterology and Nutrition, vol. 51, no. 3, pp. 322-330, 2010. 
[23] F. Guérin, T. Blanc, F. Gauthier, S. F. Abella, and S. Branchereau, "Congenital portosystemic vascular malformations," Seminars in Pediatric Surgery, vol. 21, no. 3, pp. 233-244, 2012.

[24] S. M. Hussain, T. Terkivatan, P. E. Zondervan et al., "Focal nodular hyperplasia: findings at state-of-the-art MR imaging, US, CT, and pathologic analysis," Radiographics, vol. 24, no. 1, pp. 3-17, 2004.

[25] J. E. Cheon, W. S. Kim, I. O. Kim, J. J. Jang, J. K. Seo, and K. M. Yeon, "Radiological features of focal nodular hyperplasia of the liver in children," Pediatric Radiology, vol. 28, no. 11, pp. 878883, 1998.

[26] G. O. Atkinson, M. Kodroff, P. J. Sones, and B. B. Gay, "Focal nodular hyperplasia of the liver in children: a report of three new cases," Radiology, vol. 137, no. 1 I, pp. 171-174, 1980.

[27] R. Somech, E. Brazowski, A. Kesller et al., "Focal nodular hyperplasia in children," Journal of Pediatric Gastroenterology and Nutrition, vol. 32, no. 4, pp. 480-483, 2001.

[28] P. Toma, A. Taccone, and C. Martinoli, "MRI of hepatic focal nodular hyperplasia: a report of two new cases in the pediatric age group," Pediatric Radiology, vol. 20, no. 4, pp. 267-269, 1990.

[29] Y. Yang, S. Fu, A. Li et al., "Management and surgical treatment for focal nodular hyperplasia in children," Pediatric Surgery International, vol. 24, no. 6, pp. 699-703, 2008.

[30] A. Blachar, M. P. Federle, J. V. Ferris et al., "Radiologists' performance in the diagnosis of liver tumors with central scars by using specific CT criteria," Radiology, vol. 223, no. 2, pp. 532539, 2002.

[31] H. Brisse, V. Servois, B. Bouche et al., "Hepatic regenerating nodules: a mimic of recurrent cancer in children," Pediatric Radiology, vol. 30, no. 6, pp. 386-393, 2000.

[32] D. C. Sadowski, S. S. Lee, I. R. Wanless, J. K. Kelly, and E. J. Heathcote, "Progressive type of focal nodular hyperplasia characterized by multiple tumors and recurrence," Hepatology, vol. 21, no. 4, pp. 970-975, 1995.

[33] P. Bioulac-Sage, C. Balabaud, P. Bedossa et al., "Pathological diagnosis of liver cell adenoma and focal nodular hyperplasia: Bordeaux update," Journal of Hepatology, vol. 46, no. 3, pp. 521527, 2007.

[34] V. S. Katabathina, C. O. Menias, A. K. P. Shanbhogue, J. Jagirdar, and S. R. Prasad, "Genetics and imaging of hepatocellular adenomas: 2011 update," Radiographics, vol. 31, no. 6, pp. 15291543, 2011.

[35] M. Ronot, S. Bahrami, J. Calderaro et al., "Hepatocellular adenomas: accuracy of magnetic resonance imaging and liver biopsy in subtype classification," Hepatology, vol. 53, no. 4, pp. 1182-1191, 2011.

[36] S. M. van Aalten, M. G. J. Thomeer, T. Terkivatan et al., "Hepatocellular adenomas: correlation of MR imaging findings with pathologic subtype classification," Radiology, vol. 261, no. 1, pp. 172-181, 2011.

[37] J. Calderaro, P. Labrune, G. Morcrette et al., "Molecular characterization of hepatocellular adenomas developed in patients with glycogen storage disease type i," Journal of Hepatology, vol. 58, no. 2, pp. 350-357, 2013.

[38] M. Fabre, F. Yilmaz, and M. A. Buendia, "Hepatic tumors in childhood: experience on 245 tumors and review of literature," Annales de Pathologie, vol. 24, no. 6, pp. 536-555, 2004.

[39] B. Geramizadeh, A. Bahador, H. R. Foroutan, A. Banani, S. Nikeghbalian, and S. A. Malek-Hosseini, "Pathology of pediatric liver tumors, a single center experience from south of Iran," Indian Journal of Pathology \& Microbiology, vol. 53, no. 3, pp. 422-426, 2010.
[40] D. A. Wheeler, H. A. Edmondson, and T. B. Reynolds, "Spontaneous liver cell adenoma in children," American Journal of Clinical Pathology, vol. 85, no. 1, pp. 6-12, 1986.

[41] F. I. Luks, S. Yazbeck, M. L. Brandt, A. L. Bensoussan, P. Brochu, and H. Blanchard, "Benign liver tumors in children: a 25-year experience," Journal of Pediatric Surgery, vol. 26, no. 11, pp. 1326$1330,1991$.

[42] J. H. Gold, I. J. Guzman, and J. Rosai, "Benign tumors of the liver. Pathologic examination of 45 cases," American Journal of Clinical Pathology, vol. 70, no. 1, pp. 6-17, 1978.

[43] M. B. Resnick, H. P. W. Kozakewich, and A. R. Perez-Atayde, "Hepatic adenoma in the pediatric age group: clinicopathological observations and assessment of cell proliferative activity," American Journal of Surgical Pathology, vol. 19, no. 10, pp. 11811190, 1995.

[44] H. Laumonier, P. Bioulac-Sage, C. Laurent, J. Zucman-Rossi, C. Balabaud, and H. Trillaud, "Hepatocellular adenomas: magnetic resonance imaging features as a function of molecular pathological classification," Hepatology, vol. 48, no. 3, pp. 808-818, 2008.

[45] E. M. Chung, R. Cube, R. B. Lewis, and R. M. Conran, "From the archives of the AFIP: pediatric liver masses: radiologicpathologic correlation part 1. Benign tumors," Radiographics, vol. 30, no. 3, pp. 801-826, 2010.

[46] J. F. Flejou, J. Barge, Y. Menu et al., "Liver adenomatosis. An entity distinct from liver adenoma?" Gastroenterology, vol. 89, no. 5, pp. 1132-1138, 1985.

[47] S. M. van Aalten, R. A. De Man, J. N. M. Ijzermans, and T. Terkivatan, "Systematic review of haemorrhage and rupture of hepatocellular adenomas," British Journal of Surgery, vol. 99, no. 7, pp. 911-916, 2012.

[48] L. Chiche, T. Dao, E. Salamé et al., "Liver adenomatosis: reappraisal, diagnosis, and surgical management-eight new cases and review of the literature," Annals of Surgery, vol. 231, no. 1, pp. 74-81, 2000.

[49] A. R. Kumar, J. E. Wagner, A. D. Auerbach et al., "Fatal hemorrhage from androgen-related hepatic adenoma after hematopoietic cell transplantation," Journal of Pediatric Hematology/Oncology, vol. 26, no. 1, pp. 16-18, 2004.

[50] C. D. M. Witjes, F. J. W. Ten Kate, S. M. van Aalten et al., "Hepatocellular adenoma as a risk factor for hepatocellular carcinoma in a non-cirrhotic liver: a plea against," Gut, vol. 61, no. 11, pp. 1645-1646, 2012.

[51] J. H. M. B. Stoot, E. van der Linden, O. T. Terpstra, and A. F. M. Schaapherder, "Life-saving therapy for haemorrhaging liver adenomas using selective arterial embolization," British Journal of Surgery, vol. 94, no. 10, pp. 1249-1253, 2007.

[52] P. Bioulac-Sage, H. Laumonier, G. Couchy et al., "Hepatocellular adenoma management and phenotypic classification: the Bordeaux experience," Hepatology, vol. 50, no. 2, pp. 481-489, 2009.

[53] S. Dokmak, V. Paradis, V. Vilgrain et al., "A single-center surgical experience of 122 patients with single and multiple hepatocellular adenomas," Gastroenterology, vol. 137, no. 5, pp. 1698-1705, 2009.

[54] D. Cassiman, L. Libbrecht, C. Verslype et al., "An adult male patient with multiple adenomas and a hepatocellular carcinoma: mild glycogen storage disease type Ia," Journal of Hepatology, vol. 53, no. 1, pp. 213-217, 2010.

[55] P. S. Kishnani, T. P. Chuang, D. Bali et al., "Chromosomal and genetic alterations in human hepatocellular adenomas associated with type Ia glycogen storage disease," Human Molecular Genetics, vol. 18, no. 24, pp. 4781-4790, 2009. 
[56] S. M. van Aalten, J. Verheij, T. Terkivatan, R. S. Dwarkasing, R. A. De Man, and J. N. M. Ijzermans, "Validation of a liver adenoma classification system in a tertiary referral centre: implications for clinical practice," Journal of Hepatology, vol. 55, no. 1, pp. 120-125, 2011.

[57] P. Labrune, P. Trioche, I. Duvaltier, P. Chevalier, and M. Odièvre, "Hepatocellular adenomas in glycogen storage disease type I and III: a series of 43 patients and review of the literature," Journal of Pediatric Gastroenterology and Nutrition, vol. 24, no. 3, pp. 276-279, 1997.

[58] D. Q. Wang, L. M. Fiske, C. T. Carreras, and D. A. Weinstein, "Natural history of hepatocellular adenoma formation in glycogen storage disease type i," Journal of Pediatrics, vol. 159, no. 3, pp. 442-446, 2011.

[59] V. Fritz and L. Fajas, "Metabolism and proliferation share common regulatory pathways in cancer cells," Oncogene, vol. 29, no. 31, pp. 4369-4377, 2010.

[60] J. P. Rake, G. Visser, P. Labrune, J. V. Leonard, K. Ullrich, and G. P. A. Smit, "Guidelines for management of glycogen storage disease type I-European Study on Glycogen Storage Disease Type I (ESGSD I)," European Journal of Pediatrics, vol. 161, supplement 1, pp. S112-S119, 2002.

[61] L. Bianchi, "Glycogen storage disease I and hepatocellular tumours," European Journal of Pediatrics, vol. 152, supplement 1, pp. S63-S70, 1993.

[62] B. P. Alter, "Cancer in Fanconi anemia, 1927-2001," Cancer, vol. 97, no. 2, pp. 425-440, 2003.

[63] V. Ozenne, V. Paradis, M.-P. Vullierme et al., "Liver tumours in patients with Fanconi anaemia: a report of three cases," European Journal of Gastroenterology and Hepatology, vol. 20, no. 10, pp. 1036-1039, 2008.

[64] I. Velazquez and B. P. Alter, "Androgens and liver tumors: Fanconi's anemia and non-Fanconi's conditions," American Journal of Hematology, vol. 77, no. 3, pp. 257-267, 2004.

[65] S. Kopic, K. Eirich, B. Schuster et al., "Hepatoblastoma in a 4year-old girl with Fanconi anaemia," Acta Paediatrica, vol. 100, no. 5, pp. 780-783, 2011.

[66] B. Cassinat, P. Guardiola, S. Chevret et al., "Constitutive elevation of serum alpha-fetoprotein in Fanconi anemia," Blood, vol. 96, no. 3, pp. 859-863, 2000.

[67] C. Masserot-Lureau, N. Adoui, F. Degos et al., "Incidence of liver abnormalities in Fanconi anemia patients," American Journal of Hematology, vol. 87, no. 5, pp. 547-549, 2012.

[68] Y. Bacq, E. Jacquemin, C. Balabaud et al., "Familial liver adenomatosis associated with hepatocyte nuclear factor lalpha inactivation," Gastroenterology, vol. 125, no. 5, pp. 1470-1475, 2003.

[69] Y. Reznik, T. Dao, R. Coutant et al., "Hepatocyte nuclear factor$1 \alpha$ gene inactivation: cosegregation between liver adenomatosis and diabetes phenotypes in two maturity-onset diabetes of the young (MODY)3 families," Journal of Clinical Endocrinology and Metabolism, vol. 89, no. 3, pp. 1476-1480, 2004.

[70] K. Yamagata, H. Furuta, N. Oda et al., "Mutations in the hepatocyte nuclear factor- $4 \alpha$ gene in maturity-onset diabetes of the young (MODY1)," Nature, vol. 384, no. 6608, pp. 458-460, 1996.

[71] K. Yamagata, N. Oda, P. J. Kaisaki et al., "Mutations in the hepatocyte nuclear factor- $1 \alpha$ gene in maturity-onset diabetes of the young (MODY3)," Nature, vol. 384, no. 6608, pp. 455-458, 1996.
[72] T. Kim, T. Murakami, E. Sugihara, M. Hori, K. Wakasa, and H. Nakamura, "Hepatic nodular lesions associated with abnormal development of the portal vein," American Journal of Roentgenology, vol. 183, no. 5, pp. 1333-1338, 2004.

[73] J. L. Deneve, T. M. Pawlik, S. Cunningham et al., "Liver cell adenoma: a multicenter analysis of risk factors for rupture and malignancy," Annals of Surgical Oncology, vol. 16, no. 3, pp. 640648, 2009.

[74] I. R. Marino, V. P. Scantlebury, O. Bronsther, S. Iwatsuki, and T. E. Starzl, "Total hepatectomy and liver transplant for hepatocellular adenomatosis and focal nodular hyperplasia," Transplant International, vol. 5, supplement 1, pp. S201-S205, 1992.

[75] P. J. Yunta, A. Moya, F. San-Juan et al., "A new case of hepatic adenomatosis treated with orthotopic liver transplantation," Annales de Chirurgie, vol. 126, no. 7, pp. 672-674, 2001.

[76] M. G. van Vledder, S. M. van Aalten, T. Terkivatan, R. A. De Man, T. Leertouwer, and J. N. M. Ijzermans, "Safety and efficacy of radiofrequency ablation for hepatocellular adenoma," Journal of Vascular and Interventional Radiology, vol. 22, no. 6, pp. 787793, 2011. 


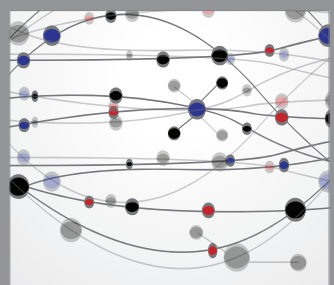

The Scientific World Journal
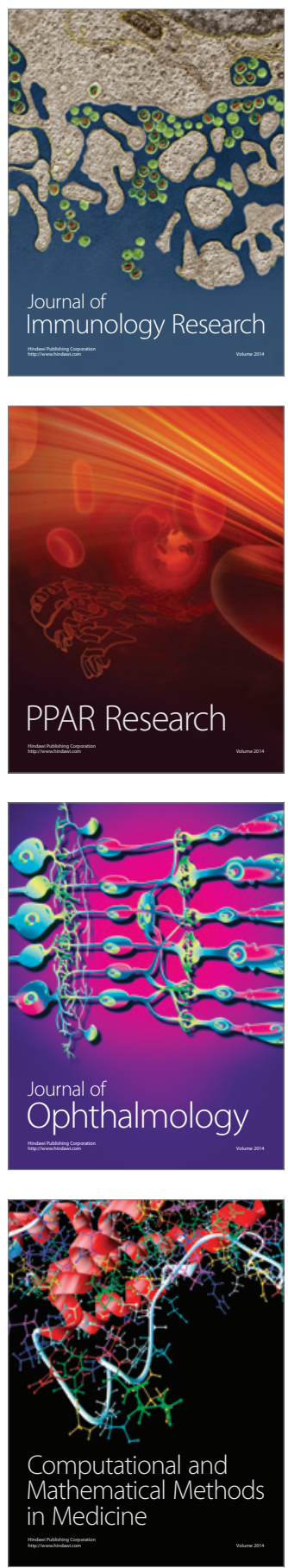

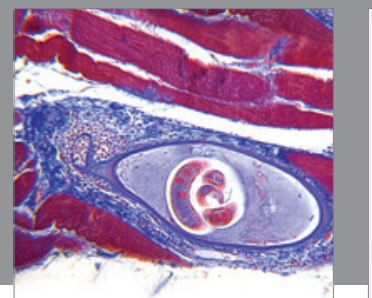

Gastroenterology

Research and Practice
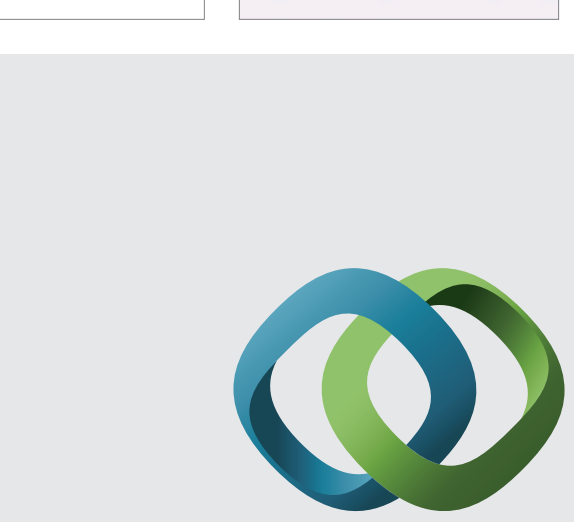

\section{Hindawi}

Submit your manuscripts at

http://www.hindawi.com
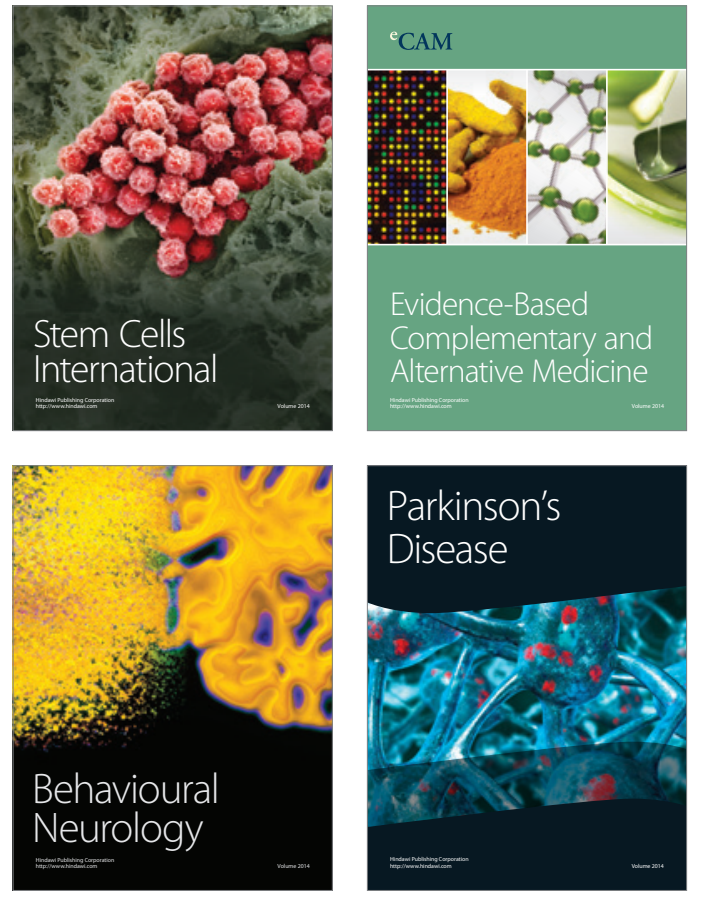
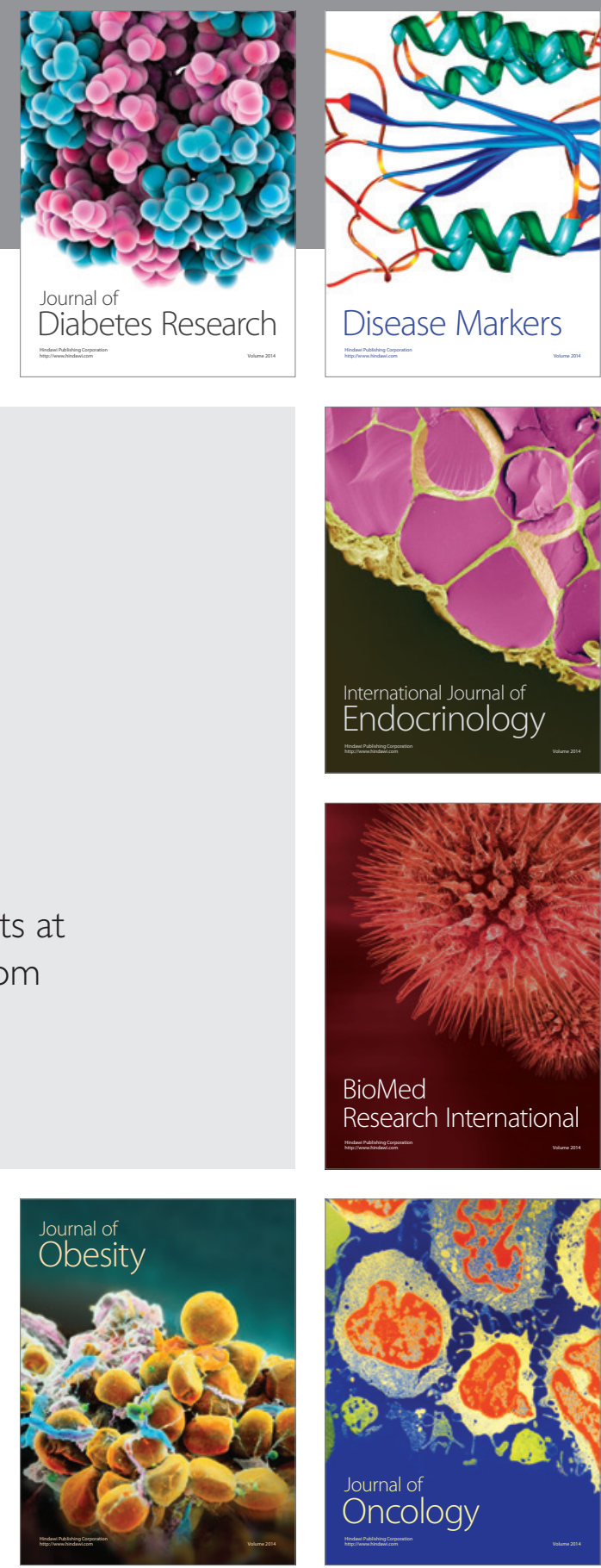

Disease Markers
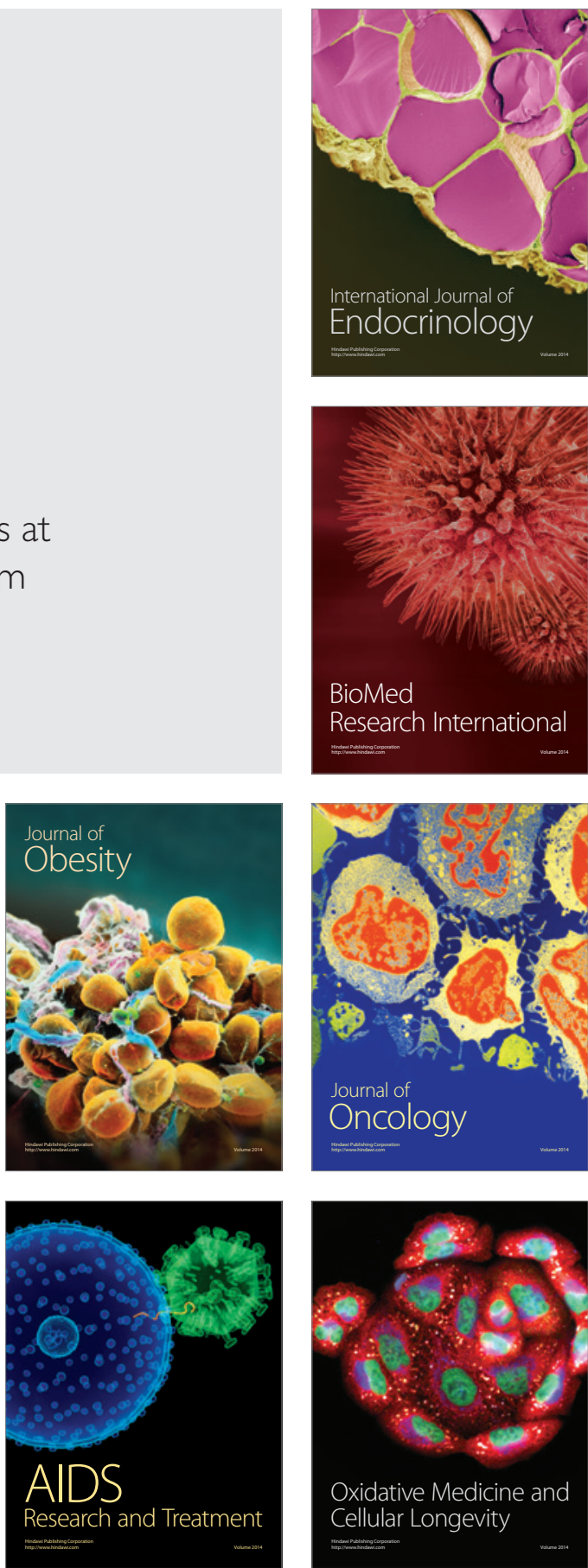